\title{
REMINERALIZATION POTENTIAL OF FUNCTIONALIZED TRICALCIUM PHOSPHATE VERSUS CASEIN PHOSPHOPEPTIDE- AMORPHOUS CALCIUM PHOSPHATE IN CARIES WHITE SPOT LESIONS "A RANDOMIZED CLINICAL TRIAL"
}

\author{
Donia M. Abd EL Moaaty*, Mohamed A. Ezzat ** and Shereen H. Ibrahim***
}

\begin{abstract}
Aim: The current study was conducted to compare between reminerlization potential of tricalcium phosphate plus fluoride versus casein-phosphopeptide/amorphous-calcium phosphate in caries white spot lesions.
\end{abstract}

Methodology: white spot lesions in anterior teeth of post orthodontic debanding patients received randomly two types of remineralizing agents, either clinpro tooth crème or MI paste plus, both materials were applied according to the manufacturer's instructions. White spot lesions were evaluated at base line one month and after 3,6 months follow up periods by two blinded assessors to assess patient satisfaction using VAS score and color change by Vita Easyhshade.

Results: One-way ANOVA followed by post-hoc Tukey's test showed that within each remineralizing agent, there was no statistically significant difference in $\mathrm{L}^{*}$ mean values between different evaluation time periods. Independent Student-t test showed that at each evaluation time, there was no statistically significant difference in $\mathrm{L}^{*}$ mean values between both remineralizing agents. Two-way ANOVA showed that the two independent variables "remineralizing agent" $(\mathrm{P}<0.004)$ and "evaluation time" $(\mathrm{P}<0.0001)$ had significant effect on patient satisfaction. However, their interaction $(\mathrm{P}=0.916)$ showed no significant effect on patient satisfaction. T6 revealed the significantly highest VAS mean values; followed by T3; then T0 and T1 which were statistically similar but at each evaluation time, there was no statistically significant difference in VAS mean values between both reminerailizing agents.

Conclusions: Under the limitation of the following trial the following conclusion can be mentioned: 1. Both clinpro tooth crème and mi paste plus has acceptable reminerlaization potential and beneficial effect in masking white spot lesions. 2 . There is improvement in patient satisfaction up to 6 months but it did not reach to the maximum patient satisfaction in masking white spot lesions.

KEYWORDS: Vita easy shade, VAS (visual analogue scale), functionalized tri calcium phosphate, Enamel remineralization, casein phsophopeptide-amorphous calcium phosphate.

* Former Internal Resident, Conservative Dentistry Department, Faculty of Dentistry, Cairo University, MSc Degree Candidate, Conservative Dentistry Department, Faculty of Dentistry, Cairo University

** Professor, Conservative Dentistry Department, Faculty of Dentistry, Cairo University

*** Associate Professor, Oral and Maxillofacial Radiology Department, Faculty of Dentistry, Cairo University 


\section{INTRODUCTION}

Dentists are frequently faced with the treatment of color aberrations of teeth, as white spot lesions which is caused by demineralization of enamel. White spot lesions prevalence of $50 \%, 60 \%$ or even $97 \%$ after bonded or banded orthodontic treatment has been reported Boersma et al.(2005) ${ }^{1}$, affecting especially labial surfaces of maxillary incisors.

The milky color of white spot lesions (WSLs) impairs dramatically the esthetic appearance thus reducing satisfaction of orthodontic therapy, making their treatment become nowadays mandatory Ellwood and Mullane (1995) ${ }^{2}$. Demineralization process cause enlargement of intercrystaline spaces results in a white spot lesion visible without air drying, Holmen et al. (1985) ${ }^{3}$.

Cosmetics and esthetics are now considered as current trends of our society, because patients now are demanding for minimally invasive cosmetic enhancement without anesthesia, drilling and less expensive restorations thus the invasive treatment of pre cavitated lesions is not required,that's why a paradigm shift of using reminerlizing agents started to mask the white spot lesions but a systematic review Sonesson $(2017)^{4}$ based on seven included studies showed that there was insufficient evidence that support remineralizing or camouflaging strategies to manage post- orthodontic white spot lesions. Well-performed clinical trials with a longer follow-up period are needed to establish best clinical practice. This was confirmed in a systematic review by Raphael and Blinkhorn (2015) ${ }^{5}$.

When CPP-ACPF is used, in the form of MI Paste plus (Milk derived phosphopeptide Infiltration), it may be a helpful adjunct in preventing or remineralizing WSLs, but the results of its efficacy are insufficient. Bailey et al. (2009) ${ }^{6}$ found that significantly more post-orthodontic WSLs regressed with the CPP-ACPF cream compared with a placebo over twelve weeks.
FTCP (functionalized tri calcium phosphate) in clinpro tooth crème prevents calcium from prematurely interacting with ionic $\mathrm{F}$ and forming calcium $\mathrm{F}$, thus providing more $\mathrm{F}$ and calcium ions to the enamel surface, Buckshey et al. (2019) ${ }^{7}$.

\section{MATERIALS AND METHODS}

\section{Study setting}

The protocol of the current study was registered in (www.clinicaltrials. gov/) database, with unique identification number NCT03823612. All procedures performed in this study, involving human participants, were in accordance with the ethical standards of Research Ethics Committee of Faculty of Dentistry, Cairo University (CREC). Ethical approval ID (1811110).This randomized controlled clinical study was held in Faculty of Dentistry, Cairo University, Egypt.

In this study, which is a randomized clinical trial the randomization was done through (www.randomization.com).

\section{Variables of the study}

The variables were two materials, MI paste plus (RECALDENT ${ }^{\mathrm{TM}}$ (CPP-ACP) plus fluoride (900ppm)) which is the control and clinpro tooth crème crème (3M ESPE) which is a $0.21 \% \mathrm{w} / \mathrm{w}$ sodium fluoride $(\mathrm{NaF})$ anti caries dentifrice that contains functionalized tricalcium phosphate (f-TCP) as an active ingredient and $950 \mathrm{ppm}$ fluoride as an intervention and they were assigned in two groups after randomization and each group has 21 teeth with white spot lesions according to the sample size calculation and each participant in this study was assessed by vita easy shade to assess the color and by visual analogue scale to assess the patient's satisfaction.

All materials used in this study as well as their specification, composition, lot number and manufacturer are listed in (Table 1). 
TABLE (1): Material's Specification, composition, manufacturer and lot number

\begin{tabular}{|l|l|l|l|l|}
\hline Material & Specification & Composition & Lot number & Manufacturer \\
\hline MI paste plus & $\begin{array}{l}\text { a special milk-derived protein that has } \\
\text { a unique ability to release bio-available } \\
\text { calcium and phosphate }\end{array}$ & $\begin{array}{l}\text { the active ingredient } \\
\text { RECALDENT } \\
\text { ACP) plus fluoride } \\
(900 \mathrm{ppm})\end{array}$ & $180503 \mathrm{~B}$ & $\begin{array}{l}\text { GC } \\
\text { http://www.gcamerica. } \\
\text { com/products/ } \\
\text { preventive/MI_Paste/ }\end{array}$ \\
\hline $\begin{array}{l}\text { Clinpro tooth } \\
\text { creme }\end{array}$ & $\begin{array}{l}\text { Contains innovative functionalized tri- } \\
\text { calcium phosphate ingredient (fTCP) } \\
\text { for optimal delivery. }\end{array}$ & $\begin{array}{l}21 \% \text { Sodium Fluoride plus } \\
\text { functionalized tri-calcium } \\
\text { phosphate ingredient } \\
\text { (fTCP) plus (950ppm F) }\end{array}$ & 80061 & $\begin{array}{l}3 \mathrm{M} \text { united states. } \\
\text { http://multimedia.3m. } \\
\text { com/mws/ } \\
\text { media/547901O/ } \\
\text { clinpro-tooth-creme- } \\
\text { technical-profile.pdf }\end{array}$ \\
\hline
\end{tabular}

Participants were randomized to ensure the allocation concealment, by making opaque sealed envelopes containing the grouping generated previously and titled by numbers as the randomization codes were not released until the participants had been recruited into the trial. Patients who met the inclusion criteria were enrolled into the study by the assessors.

It was a triple blinded study as the patients, assessors and the statistician were blinded, The patients were given the tooth paste or crème inside $\mathrm{a}$ plastic syringe in order not to know the material used. All procedures performed in this study, involving human participants, were in accordance with the ethical standards of Research Ethics Committee of Faculty of Dentistry, Cairo University (CREC).

\section{Sample size calculation:}

Based on a previous study by Bailey (2012) the difference in shade change between the 2 groups is 6 \pm 6 . Using power $80 \%$ and $5 \%$ significance level we will need to study 17 in each group. This number is to be increased to a sample size of 21 to compensate for losses during follow up. The calculation of the sample size was done using Power and Sample Size Calculation Software Version 3.1.2 (Vanderbilt University, Nashville, Tennessee, USA

\section{Eligibility criteria:}

The patients in this study were selected following different exclusion and inclusion criteria

\section{Inclusion criteria of the participants:}

- Between the ages of 12 and 25 years of age female and males

- Had received conventional periodontal therapy after orthodontic treatment

- Active carious white spot lesions

- Had completed fixed orthodontic treatment (2-6 months)

- No systemic diseases or concomitant medication affecting salivary flow,

\section{Exclusion criteria of the participants:}

- Participant in another trial

- Non carious lesion (enamel hypoplasia and dental flourosis)

- Presence of tetracycline pigmentation.

- Participants who had evidence of reduced salivary flow or significant tooth wear-high caries index

- Allergy to MI paste plus or clinpro tooth creme being used in the study 


\section{Material Application}

The selected product either clinpro tooth crème or MI paste plus was brushed on for 2 minutes twice daily for 6 months. They were instructed to add the either tooth crème or paste inside an insulin syringe and use only 20 units on each time on the tooth brush. After brushing using either product, patients were instructed not to rinse their mouths with water but they were requested to expectorate the paste from their mouth to enable the product to be available for a longer period of time on the tooth surface. Patients also were asked not to eat rather drink for half an hour following the treatment.

\section{Primary outcome: assessment of color change of} white spot lesions:

Visual color assessment was performed using the Vita Easyshade Spectrophotometer Compact (Vita Zahnfabrik, Bad Sa"ckingen,Germany) Odaira et al.(2011) ${ }^{8}$. Calibration of the device was done before each appointment with the aid of white table given by the manufacturer. Each white spot lesion was measured by holding the probe tip at a right angle to the whole surface and the values were reported as shown in figure 1 . To minimize measurement errors, the assessments were repeated three times, and the mean values of three consecutive measurements were recorded for each area. Only the $\mathrm{L}^{*}$ value was captured in this study. The $\mathrm{L}^{*}$ axis describes the degree of lightness inside the sample and it ranges from 0 which denotes black to 100 which denotes white. Thus, the higher the $\mathrm{L}^{*}$ value, the whiter the lesion, which indicates a higher degree of enamel demineralization. On the other hand, lower $\mathrm{L}^{*}$ values

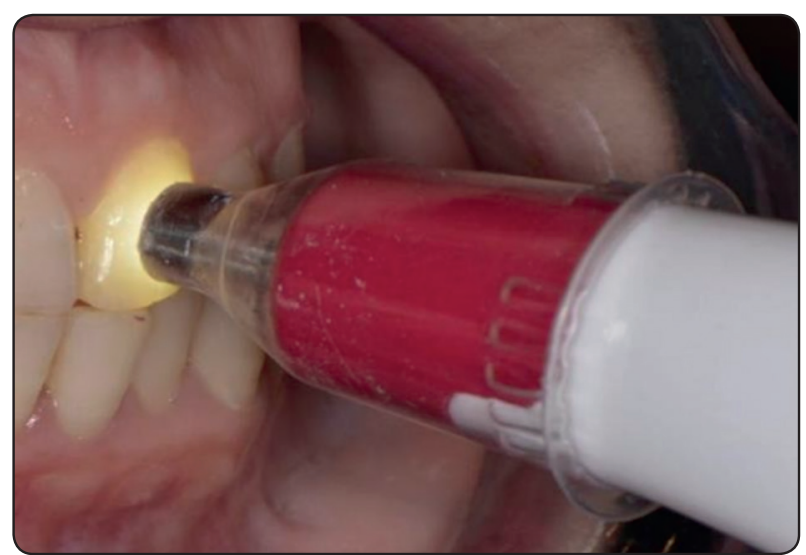

Fig. (1) Color change assessment

indicate a masking color effect, that is, the surface color becomes less white and is closer to the tooth color. The color measurements were performed in three distinct times: baseline before any treatment, 1, 3 and 6 months, Horuztepe andBaseren (2017) ${ }^{9}$.

\section{Secondary outcome: assessment of patient satisfaction}

Patient satisfaction was measured using visual analogue score (VAS) scores at baseline(T0), 1 months (T1), 3 months (T3) and 6 months (T3). VAS scores were classified as follows highly satisfied (HS), 8-10 points; satisfied (S), 5-7 points; and not satisfied (NS), $<5$ points.orVAS scores were classified as follows ${ }^{(\mathrm{R})}$ : satisfied (5-10 points); and not satisfied ( $<5$ points) Nie $\mathbf{J}$ et al. (2017) ${ }^{\mathbf{1 0}}$. The mean and standard deviation for the VAS scores of the patients recorded preoperatively as shown in figure 2.

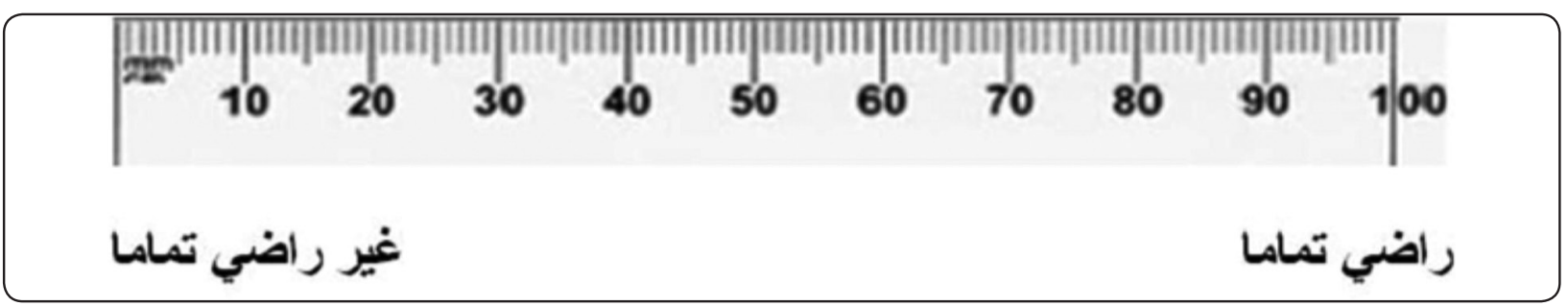

Fig. (2) color change assessment 


\section{Statistical analysis}

It was performed using IBM SPSS Statistics Version 2.1 for Windows. Data was described in the form of mean and standard deviation (SD). The significance level was set when the P value is less than 0.05 .

Two-way ANOVA test was performed to evaluate the effect of the two study variables and their interaction on color change and patient satisfaction. One-way ANOVA followed by post-hoc Tukey's test were used to compare $\mathrm{L}^{*}$ values at different evaluation time periods within each remineralizing agent. Independent Student-t test was performed to compare $\mathrm{L}^{*}$ values between both remineralizing agents at each evaluation time period. KruskalWallis followed by Bonferroni-corrected Wilcoxon Signed-Rank test were conducted to compare patient satisfaction assessed by visual analogue scale (VAS) at different evaluation time periods within each remineralizing agent. Mann- Whitney test was used to compare VAS scores between both remineralizing agents at each evaluation time period. One-way ANOVA followed by post-hoc Tukey's test showed that within each remineralizing agent, there was no statistically significant difference in $\mathrm{L}^{*}$ mean values between different evaluation time periods.

\section{RESULTS}

\section{Regarding color change:}

Two-way ANOVA (Table 2) showed that the two independent variables "remineralizing agent" $(\mathrm{P}<0.060)$ and "evaluation time" $(\mathrm{P}<0.118)$ and their interaction $(\mathrm{P}<0.976)$ had no significant effect on color change.

\section{Effect of different evaluation time periods on pa- tient satisfaction within each remineralizing agent}

Kruskal-Wallis followed by Bonferroni-corrected Wilcoxon Signed-Rank test showed that within both remineralizing agents, T6 revealed the significantly highest VAS mean values; followed by T3; then $\mathrm{T} 0$ and $\mathrm{T} 1$ which were statistically similar.
TABLE (2): Mean \pm St. deviation of VAS scores and $\mathrm{P}$-value for the effect of different evaluation time periods on patient satisfaction within each remineralizing agent.

\begin{tabular}{|l|l|l|}
\hline & MI paste plus & Clinpro tooth crème \\
\hline T0 & $3.52 \pm 0.60^{\mathrm{a}}$ & $3.14 \pm 0.91^{\mathrm{a}}$ \\
\hline T1 & $3.57 \pm 0.59^{\mathrm{a}}$ & $3.19 \pm 0.92^{\mathrm{a}}$ \\
\hline T3 & $4.52 \pm 0.81^{\mathrm{b}}$ & $4.19 \pm 0.67^{\mathrm{b}}$ \\
\hline T6 & $6.52 \pm 0.51^{\mathrm{c}}$ & $6.33 \pm 0.48^{\mathrm{c}}$ \\
\hline P-value & $<0.0001^{*}$ & $<0.0001^{*}$ \\
\hline
\end{tabular}

*: significant $(P \leq 0.05)$

\section{Regarding patient satisfaction}

Two-way ANOVA (Table7) showed that the two independent variables "remineralizing agent" $(\mathrm{P}<0.004)$ and "evaluation time" $(\mathrm{P}<0.0001)$ had a significant effect on patient satisfaction. However, their interaction $(\mathrm{P}=0.916)$ showed no significant effect on patient satisfaction.

\section{Effect of remineralizing agent on patient satis- faction at each evaluation time period}

Mann-Whitney test (table 3) showed that at each evaluation time, there was no statistically significant difference in VAS mean values between both remenieralizing agents.

TABLE (3): Mean \pm St. Deviation of VAS scores and P-value for the effect of remineralizing agent on patient satisfaction at each evaluation time period.

\begin{tabular}{|l|c|c|c|c|}
\hline & T0 & T1 & T3 & T6 \\
\hline MI paste plus & $3.52 \pm 0.60$ & $3.57 \pm 0.59$ & $4.52 \pm 0.81$ & $6.52 \pm 0.51$ \\
\hline $\begin{array}{l}\text { Clinpro tooth } \\
\text { crème }\end{array}$ & $3.14 \pm 0.91$ & $3.19 \pm 0.92$ & $4.19 \pm 0.67$ & $6.33 \pm 0.48$ \\
\hline P-value & $0.151 \mathrm{NS}$ & $<0.170 \mathrm{NS}$ & $<0.161 \mathrm{NS}$ & $0.218 \mathrm{NS}$ \\
\hline
\end{tabular}




\section{Correlation between colour change and patient satisfaction}

Pearson's correlation test revealed that there was no correlation between color change and patient satisfaction $(\mathrm{P}=0.129, \mathrm{r}=0.118)$

\section{DISCUSSION}

White spot lesion is an optical phenomenon due to subsurface tissue loss. Surface features of active initial enamel carious lesions show widened intercrystalline spaces with lower interprismatic mineral content in the surface layer Haghgoo et al. $(2017)^{11}$

The aim of the study was to evaluate the Reminerlization potential of Tri calcium phosphate plus fluoride versus casein-phosphopeptide/amorphouscalcium phosphate in caries white spot lesions.

The white spot lesions used in this study were active as Active white spot lesions usually have a better prognosis to recover the translucency of the enamel than arrested white spot lesions because of their porosity and therefore easier penetration of calcium phosphate ions Fejerstkov et al. $(\mathbf{2 0 0 3})^{12}$

Philip et al. (2018) ${ }^{13}$ showed that the need for developing newer approaches to remineralize enamel caries lesions, while fluoride mediated natural repair of early lesions can occur by the present oral hygiene and diet that are highly influencing, this mainly depends on many variables such as the quality of the saliva and the compliance of the patients, however non- fluoride remineralization systems are less reliant on such factors.

Casein Phosphopeptide Amorphous Calcium Phosphate (CPP-ACP) is a nanocluster that binds calcium and phosphate ions in an amorphous form. Once $\mathrm{pH}$ drops in the oral cavity, the calcium and phosphate ions are released to produce a supersaturated concentration of ions in the saliva, which precipitates a calcium-phosphate compound onto the exposed tooth surface, Casein phosphopeptide amorphous calcium phosphate acts by binding to the tooth surface and plaque. This binding process is maintaining a high concentration gradients of soluble calcium and phosphate ions as a result of the stabilization of the amorphous calcium phosphate, both of which play an integral role in remineralization. These calcium and phosphate ions are deposited in the voids inside the crystal in the enamel and promote crystal growth, which has a positive impact on the reflective properties of the enamel, Aimutis et al. (2004) ${ }^{14}$. Bailey et al. (2009) ${ }^{15}$ also found that significantly more post-orthodontic WSLs regressed with the CPP-ACP cream compared with a placebo over twelve weeks but another in vitro study found that on application of CPP-ACP paste to teeth surface a layer that fills the interprismatic cavities was formed, preventing dental erosion and acid attack by soft drinks, Poggio et al. (2009) ${ }^{16}$.

A recent in vivo study of WSLs after debonding of orthodontic appliances demonstrated a significant reduction in fluorescence and reduced area of lesions after daily application of CPP-ACP paste for a four weeks' time span, Brochner et al .(2011) ${ }^{17}$.

Similarly, Robertson et al .(2011) ${ }^{18}$ in a prospective randomized controlled trial, found that the use of MI Paste Plus (MI Paste with Fluoride) during orthodontic treatment not only decreased the number of the present white spot lesions but it also prevented the development of new ones. However, Pulido et al $\mathbf{. 2 0 0 8}^{\mathbf{1 9}}$ found that there was no significant difference between the artificial saliva and MI paste group in reducing carious lesion progression

Previously performed studies indicated decreased demineralization around orthodontic brackets in vitro, and decrease of WSLs visually following topical application of agents containing CCPACP complexes in vivo. Bailey et al. (2009) ${ }^{20}$

Clinpro tooth crème (3M ESPE) is composed of $0.21 \% \mathrm{w} / \mathrm{w}$ sodium fluoride $(\mathrm{NaF})$ and it is considered as anti caries dentifrice that contains $950 \mathrm{ppm}$ fluoride and a functionalized tricalcium phosphate (f-TCP) ingredient. One of the most 
important advantage of this calcium phosphate system is being stable in an aqueous environment and also does not affect the fluoride activity added in the dentifrices. Also, it has been advised to combine the flouride with f-TCP and this will not only provides greater RML in terms of microhardness and fluoride uptake, but it also is decreasing the fluoride dose that is required to achieve the same degree of reminerlization. Karlinsey et al. (2010) $)^{21}$

The results in the current study showed that the effect of remineralizing agent on color change at each evaluation time period is there was no statistically significant difference in $\mathrm{L}^{*}$ mean values between both remineralizing agents.

Research has revealed a decrease in the size of white spot lesions over time without the usage of any products directed at their resolution. Resolution is thought to occur via 2 mechanisms: the first one is the concentration of various soluble ions in saliva, particularly calcium, phosphate, and fluoride, which promote remineralization of the lesions and the second mechanism is by surface abrasion to remove the dissolved surface enamel of the lesion, exposing the underlying enamel crystals, which are tightly packed and thus provide proper light reflection. Karlinsey et al. (2010) $)^{21}$

Reynolds et al. (2008) ${ }^{22}$ which somehow agree with my results as it showed some improvement in the lesion size. In the presence of fluoride, CPP- ACP has been shown that it is able to promote the formation of fluorapatite deep in the subsurface lesion. Hence, this ability to promote remineralization of enamel subsurface lesions in situ explains the significant regression of whitespot lesions by CPP-ACP in this post- orthodontic population using fluoride toothpaste and receiving supervised fluoride mouthrinses

Shanthraj et al. (2019) $)^{23}$ performed a study showing that Clinpro tooth crème showed remineralization potential on white spot lesions. Even though it was not statically significant that agree with the results of the current study and it showed that Tooth mousse tooth crème and Clinpro tooth crème showed remineralization potential on white spot lesion. Even though mean Gloss meter values are not statistically significant, higher Gloss meter values and statistically significant Profilometer values suggest Tooth mousse, tooth crème, toothpaste has higher remineralization potential compared to Clinpro tooth crème and the justification of these results was because of the combined effect of CPP-ACP and fluoride which was not there in all other groups. Karlinsey et al .(2009) ${ }^{24}$,reported that the combination of sodium fluoride with fTCP in a simple aqueous solution is capable of producing significantly greater surface and subsurface rehardening of white spot lesions than the usage of fluoride alone. This result is similar to our findings.

A study was done in order to detect the effect of the following materials: Clinpro 5000 tooth crème, Clinpro Tooth Creme, and MI- Paste Plus on 'the formation of white spot lesions in patients undergoing orthodontic treatment the results of this study showed that the use of Clinpro 5000, Clinpro Creme, and MI paste Plus all have a reduction effect on white spot lesions that disagree with my results with superior effect to Clinpro 5000 Kau et al. (2019) ${ }^{25}$

The participant's satisfaction was primary assessed in this study because public perception is considered as the main factor that drives the demand for the esthetic dental treatment. Ensures that research outcome is patient relevant. The classic study by Dr. Ronald Goldstein published in 1969 was the first to correlate dental esthetics and patient perception, Benson (2008) ${ }^{26}$.

Visual analogue scale (VAS) considered reliable method to record the patient satisfaction before and after the treatment. This method is simple, easy to be used by participants in addition to its accuracy than the verbal analogue scale Brokelman et al. (2012) ${ }^{27}$. 
The outcomes of this current study agree with the results of some clinical trials. Robertson et al .(2011) ${ }^{18}$ found that the usage of MI Paste Plus was able to prevent the development of new white spot lesions during orthodontic treatment and reduced the number of WSLs already present, whereas the placebo paste showed no significant effect on the prevention and treatment of caries lesions.

Patient retention and dental management strategies were carried out to ensure accurate patient record, self-patient education and more professional data entry and to prevent loss of data. Despite the inherent subjectively in valuing outcome of white spot lesions treatment, the most studies have been focused on physical properties and effectiveness of remineralization, and ignored the perception of patients. The VAS score results showed there was no statistically significant value between both two groups But the VAS score increased significantly in both groups in $\mathrm{T} 6$ followed by $\mathrm{T} 3$ then $\mathrm{T} 0$ and $\mathrm{T} 1$ which are statistically similar

The results in this curent study have indicated that twice daily topical applications of CPP- ACPF paste as an adjunct to the standard oral hygiene programme insignificantly improved the visual appearance and remineralisation of the WSLs but not to the extent which is in disagreement of an in vivo study that evaluated the impact of $10 \% \mathrm{CPP}$ $\mathrm{ACP}$ and $5 \%$ sodium fluoride varnish regimes on the regression of nonorthodontic white spot lesions (WSLs) Guclu et al. (2016) ${ }^{28}$. These findings are matched with the findings of those previous in vivo studies in which the cosmetic appearance, extent of remineralisation, and/or size of incipient lesions were improved when topical applications of CPP- ACP paste were used to supplement good oral hygiene protocols in which the daily use of fluoridated dentifrices was incorporated Guclu et al. (2016) ${ }^{28}$.
There is a remarkable discrepancies in the literature regarding the clinical relevance in both the activity, extent and severity of lesions, and the possible pathological dissimilarities between orthodontic and nonorthodontic WSLs. Guclu et al. (2016) ${ }^{28}$.

This clinical study had some limitations. One of the major limitations is the patients' compliance that could not be ideally controlled. A trial was done to overcome the compliance barrier by giving the patients brushing technique instructions, standardizing the time and frequency for brushing, and using the brushing diary as a method to control their actual compliance with the protocol.

By the end of the discussion our null hypothesis was accepted that there is no significant difference between the reminerlization potential of clinpro tooth crème and MI paste plus on caries white spot lesions.

\section{CONCLUSIONS}

Under the limitation of the following trial the following conclusion can be mentioned:

1. Both clinpro tooth crème and mi paste plus has acceptable reminerlaization potential and beneficial effect in masking white spot lesions

2. There is gradual increase in patient satisfaction up to 6 months but it did not reach to the maximum patient satisfaction in masking white spot lesions.

At the end of the follow up period of this trial all the patients were satisfied of their esthetic appearance.

\section{RECOMMENDATION}

Further clinical trials with longer follow up period are recommended to see if the masking of the white spot lesions will be better with higher patient satisfaction scores 


\section{REFERENCES}

1. Boersma J, van der Veen M, Lagerweij M, Bokhout B, Prahl-Andersen B. (2005). Caries prevalence measured with QLF after treatment, with fixed orthodontic appliances: influencing factors. Caries Research, 39: 41-47

2. Ellwood, R, \& O’Mullane D. (1995). Enamel opacities and dental esthetics.Journal Public Health Dentistry, 55(3): 171-176.

3. Holmen L, Thylstrup A, Ogaard B, \& Kragh F. (1985). A scanning electron microscopic study of progressive stages of enamel caries in vivo. Caries Research, 19(4): 355-367.

4. Sonesson M, Bergstrand F, Gizani S, Twetman S. (2017). Management of post- orthodontic white spot lesions: an updated systematic review. European journal of orthodontics, 39(2): 116-121.

5. Raphael S, Blinkhorn A. (2015). Is there a place for Tooth Mousse ${ }^{\circledR}$ in the prevention and treatment of early dental caries, a systematic review. BMC Oral Health, 15(1): 113-124

6. Bailey, M. W. (2012). Effectiveness of Resin Infiltration and Mi Paste Cpp-Acp in Masking White Spot Lesions, p43-44

7. Buckshey, S., Anthonappa, R. P., King, N. M., \& Itthagarun, A. (2019). Remineralizing Potential of Clinpro® and Tooth Mousse Plus ${ }^{\circledR}$ on Artificial Carious Lesions. Journal of Clinical Pediatric Dentistry, 43(2), 103-108.

8. Odaira, C., Itoh, S., \& Ishibashi, K. (2011). Clinical evaluation of a dental color analysis system: the Crystaleye Spectrophotometer ${ }^{\circledR}$. Journal of prosthodontic research, 55(4), 199-205

9. Horuztepe, S. A., \& Baseren, M. (2017). Effect of resin infiltration on the color and microhardness of bleached white-spot lesions in bovine enamel (an in vitro study). Journal of Esthetic and Restorative Dentistry, 29(5), 378385 .

10. Nie, J., Tian, F. C., Wang, Z. H., Yap, A. U., \& Wang, X. Y. (2017). Comparison of efficacy and outcome satisfaction between in-office and home teeth bleaching in Chinese patients. Journal of oral Science, 59(4), 527-532.

11. Haghgoo, R., Mehran, M., Ahmadvand, M., \& Ahmadvand, M. J. (2016). Remineralization effect of eggshell versus nano-hydroxyapatite on caries-like lesions in permanent teeth (in vitro). Journal of International Oral Health, $8(4), 435$.
12. Fejerskov O, Kidd E. (2003). Dental caries: the disease and its clinical management. Copenhagen, Denmark: Blackwell Munksgaard. Journal of Dental Research, 38: (35-38).

13. Philip, N. (2019). State of the art enamel remineralization systems: the next frontier in caries management. Caries research, 53(3), 284-295.

14. Aimutis, W. R. (2004). Bioactive properties of milk proteins with particular focus on anticariogenesis. The Journal of nutrition, 134(4), 989S-995S.

15. Bailey, M. W. (2012). Effectiveness of Resin Infiltration and Mi Paste Cpp-Acp in Masking White Spot Lesions, p43-44

16. Poggio, C., Lombardini, M., Dagna, A., Chiesa, M., \& Bianchi, S. (2009). Protective effect on enamel demineralization of a CPP-ACP paste: an AFM in vitro study. Journal of dentistry, 37(12), 949-954.

17. Bröchner, A., Christensen, C., Kristensen, B., Tranæus, S., Karlsson, L., Sonnesen, L. and Twetman, S., 2011. Treatment of post-orthodontic white spot lesions with casein phosphopeptide-stabilised amorphous calcium phosphate. Clinical oral investigations, 15(3), pp.369-373.

18. Robertson, M. A., Kau, C. H., English, J. D., Lee, R. P., Powers, J., \& Nguyen, J. T. (2011). MI Paste Plus to prevent demineralization in orthodontic patients: a prospective randomized controlled trial. American Journal of orthodontics and dentofacial orthopedics, 140(5), 660-668.

19. Pulido, M. T., Wefel, J. S., Hernandez, M. M., Denehy, G. E., Guzman-Armstrong, S., Chalmers, J. M., \& Qian, F. (2008). The inhibitory effect of MI paste, fluoride and a combination of both on the progression of artificial carieslike lesions in enamel. Operative dentistry, 33(5), 550-555.

20. Bailey, M. W. (2012). Effectiveness of Resin Infiltration and Mi Paste Cpp-Acp in Masking White Spot Lesions, p $43-44$

21. Karlinsey, R. L., Mackey, A. C., \& Stookey, G. K. (2009). In vitro remineralization efficacy of $\mathrm{NaF}$ systems containing unique forms of calcium. American journal of dentistry, 22(3), 185-188

22. Reynolds, E. C., Cai, F., Cochrane, N. J., Shen, P., Walker, G. D., Morgan, M. V., \& Reynolds, C. (2008). Fluoride and casein phosphopeptide-amorphous calcium phosphate. Journal of Dental Research, 87(4), 344-348.

23. Shanthraj R,Jose B, Joshy K,(2019). Evaluation of three commercially available toothpaste/creams for resolution of 
white spot lesions - An in vitro study. International Journal of Advance Research, Ideas and Innovations in Technology, 5(2):2056-2059

24. Karlinsey, R. L., Mackey, A. C., Walker, E. R., \& Frederick, K. E. (2010). Preparation, characterization and in vitro efficacy of an acid-modified $\beta$-TCP material for dental hard-tissue remineralization. Acta Biomaterialia, 6(3), 969-978.

25. Kau, C. H., Wang, J., Palombini, A., Abou-Kheir, N., \& Christou, T. (2019). Effect of fluoride dentifrices on white spot lesions during orthodontic treatment: A randomized trial. The Angle Orthodontist, 89(3), 365-371.
26. Benson P. (2008). Evaluation of White Spot Lesions on Teeth with Orthodontic Brackets, Seminars in Orthodontics, 14(3): 200-208.

27. Brokelman, R. B., Haverkamp, D., van Loon, C., Hol, A., van Kampen, A., \& Veth, R. (2012). The validation of the visual analogue scale for patient satisfaction after total hip arthroplasty. European orthopaedics and traumatology, 3(2), 101-105.

28. Guclu Z, Alacam A, and Coleman A, (2016). A 12-Week Assessment of the Treatment of White Spot Lesions with CPP-ACP Paste and/ or Fluoride Varnish. BioMed Research International, 2016, 1-9 